\title{
Sarah Charieyras, Le dit et le non-dit dans "L'Usage de la parole" de Nathalie Sarraute
}

\section{Emanuele Kanceff}

\section{Q OpenEdition}

1 Journals

\section{Edizione digitale}

URL: https://journals.openedition.org/studifrancesi/26816

DOI: $10.4000 /$ studifrancesi.26816

ISSN: 2421-5856

\section{Editore}

Rosenberg \& Sellier

\section{Edizione cartacea}

Data di pubblicazione: 1 avril 2007

Paginazione: 214

ISSN: 0039-2944

\section{Notizia bibliografica digitale}

Emanuele Kanceff, "Sarah Charieyras, Le dit et le non-dit dans "L'Usage de la parole" de Nathalie Sarraute», Studi Francesi [Online], 151 (LI | I) | 2007, online dal 30 novembre 2015, consultato il 23 novembre 2021. URL: http://journals.openedition.org/studifrancesi/26816 ; DOI: https://doi.org/ 10.4000/studifrancesi.26816

Questo documento è stato generato automaticamente il 23 novembre 2021.

\section{(c)}

Studi Francesi è distribuita con Licenza Creative Commons Attribuzione - Non commerciale - Non opere derivate 4.0 Internazionale. 


\title{
Sarah Charieyras, Le dit et le non-dit dans "L'Usage de la parole" de Nathalie Sarraute
}

\author{
Emanuele Kanceff
}

\section{NOTIZIA}

SARAH CHARIEYRAS, Le dit et le non-dit dans "L'Usage de la parole" de Nathalie Sarraute, Caen, Lettres Modernes Minard, 2006, pp. 97 (“Archives des lettres modernes”, 286).

1 L'Usage de la parole viene pubblicato nel 1980 e, visto da vicino, non appartiene né ad un registro sociologico né ad uno didattico. Sembra piuttosto appartenere ad un genere non lontano dal romanzo, anche se si alimenta di generi diversi, teatro, poesia, saggio. Il lavoro di Sarah Charieyras mette a confronto due piani differenti, in modo parallelo, studiandoli sia dal punto di vista dei personaggi che delle sensazioni che stanno sotto le conversazioni, percorrendo le diverse ipotesi che ne scaturiscono. Sarraute può aver preferito rispettare in parte il silenzio perché il suo interlocutore, vivendo i tropismi, sa che cosa sono; oppure, sono i tropismi stessi che non sopportano di essere detti esplicitamente, preferendo svilupparsi nel sentito, poiché l'implicito non li nasconde ma li evidenzia maggiormente. Forse la scrittrice sceglie sapientemente di non dire tutto, forse vi è costretta dall'indicibilità del suo soggetto, che non le lascia scelta.

2 Per dare risposta a questi interrogativi, l'autrice cerca prima di tutto di provare la presenza di istanze enunciative nel libro, studiandone il numero, l'identità e la natura. In seguito, si sforza di valutare la parte negativa di quanto viene detto - il non detto precisando le forme che riveste e le figure di cui si serve. Infine, si preoccupa di precisare il carattere inseparabile del detto e del non detto, formando l'immagine di una poetica che pencola tra chiusura e dinamismo pieno di energia. 